\title{
Association of Class II Human Histocompatibility Leukocyte Antigens with Rheumatic Fever
}

\author{
Elia M. Ayoub, Douglas J. Barrett, Noel K. Maclaren, and Jeffrey P. Krischer \\ Departments of Pediatrics and Pathology, University of Florida School of Medicine, Gainesville, Florida 32610
}

\begin{abstract}
The association of class I and II HLA antigens with rheumatic fever and its manifestations was examined in 72 patients, including 48 blacks and 24 Caucasians. No significant association was found between class I antigens and rheumatic fever. In contrast, HLA-DR2 and HLA-DR4 phenotypes were encountered in a significantly higher frequency in black and Caucasian patients with rheumatic fever, respectively, compared with the control populations $(P<0.005)$. The most significant association $(P$ $<0.005)$ of these DR antigens with a major manifestation of rheumatic fever was found for mitral insufficiency. In addition, a significant association was encountered between persistent elevation of antibody to the group $A$ streptococcal carbohydrate and HLA-DR4 in Caucasian patients $(P<0.04)$ or HLA-DR2 in the black patients $(P<0.001)$. The frequency of HLA-DR2/ 4 heterozygotes among patients with rheumatic fever did not differ significantly from controls. These findings support the concept of a genetically determined susceptibility to rheumatic fever and, particularly, to rheumatic heart disease. The association of the clinical manifestations of rheumatic fever and the immune hyperresponsiveness to a streptococcal antigen could be ascribed to a disease-associated immune-response gene which is in linkage disequilibrium with the DR2 and DR4 alleles of HLA-DR locus on chromosome six.
\end{abstract}

\section{Introduction}

Numerous epidemiological studies indicating a high familial incidence suggest that hereditary factors may determine susceptibility to rheumatic fever (1-3). Early but unconfirmed studies suggested that susceptibility to rheumatic fever followed a simple autosomal recessive pattern of inheritance (4-6), or paralleled the inheritance of $\mathrm{ABO}$ blood group or $\mathrm{ABO}$ secretor status (717). The pathogenesis of rheumatic fever is also thought to involve an aberrant immunological reaction, either humoral or cellular, or both, triggered by an antecedant group A streptococcal infection (18-25). Since cell surface antigens encoded by the genes of the major histocompatibility complex are known to be important in controlling immunological responsiveness, recent genetic studies have examined the association between rheumatic fever and HLA antigens. Initial studies examined the frequency of class I (HLA-A, B) antigens in patients with rheumatic fever, but no consistent association between these antigens and rheumatic fever was found (26-33).

Address reprint requests to Dr. Ayoub, Department of Pediatrics, Box J-296, JHMHC, University of Florida, Gainesville, FL 32610.

Received for publication 30 September 1985 and in revised form 9 January 1986.

J. Clin. Invest.

(c) The American Society for Clinical Investigation, Inc.

$0021-9738 / 86 / 06 / 2019 / 08 \quad \$ 1.00$

Volume 77, June 1986, 2019-2026
To test for possible associations between the class II HLA antigens and rheumatic fever, we performed HLA-DR typing of patients with rheumatic fever and normal individuals. A significant association between rheumatic fever and the expression of HLA-DR2 in blacks and HLA-DR4 in Caucasians was found. Furthermore, the expression of these two DR antigens was associated with serological hyperresponsiveness to the group A streptococcal polysaccharide antigen. Our results are consistent with the hypothesis that susceptibility to rheumatic fever is genetically linked and may be associated with an HLA-associated immune hyperresponsiveness to a streptococcal antigen.

\section{Methods}

Patient selection. Patients attending the rheumatic fever clinics of the University of Florida Health Center and of the Children's Medical Services were asked to participate in the study. All patients presented initially with an illness which fulfilled the modified Jones criteria for the diagnosis of acute rheumatic fever (34). All of the patients were studied during the chronic phase of their illness, from 1 to $15 \mathrm{yr}$ after initial diagnosis. A total of 72 patients were studied, including 24 Caucasians and 48 blacks. The demographic data and the major manifestations with which these patients presented are outlined in Table I. Cardiac involvement was classified as being persistent or transient, based on the clinical findings at the time of the patient's acute episode and the status of the cardiac findings at the time of enrollment in the study.

Controls for HLA typing consisted of healthy young adults and adult volunteers who resided in the same geographic area. The controls comprised 285 Caucasians and 64 blacks.

Written informed consent was obtained either from the patient or his guardian before enrollment in the study.

HLA typing. Typing for HLA was performed as described previously (Rotter, J. I., W. J. Riley, C. M. Vadheim, R. Spillar, and M. C. Mengel, unpublished data presented in part to the American Diabetes Association Annual Scientific Meeting, Las Vegas, June 1984). Heparinized blood was collected and processed for typing of leukocyte antigens within 24 $h$ on all samples. In the majority of cases (80-90\%), typing was performed on the day of blood sampling. The microcytotoxicity methods of Amos (35) and Terasaki (36) were used for identification of class I antigens (A, B, C alleles). Class I antisera were obtained from the National Institutes of Health (HLA Typing Bank), local sources, and by serum exchange with Dr. Rene Duquesnoy of the Milwaukee Blood Bank (Milwaukee, WI). The double microfluorescent procedure of van Rood (37) and Terasaki (Terasaki, P. I., 1980, histocompatibility testing, University of California at Los Angeles Tissue Typing Laboratory, unpublished data) were used to detect class II antigens (DR and MT alleles). Approximately $90 \%$ of the patients' samples were studied using Terasaki trays to detect B cell or DR alloreactivity. Others were studied using trays with maternally derived alloantisera developed at the University of Florida and antisera kindly provided by Dr. Duquesnoy. Multiple antisera for specificities DR1 through DR8 were available for typing all subjects throughout the study, whereas antisera for specificities DRW9 and DRW10 were available for most, but not all, of the patients and controls. Sera identified as typespecific by the Eighth International Histocompatibility Workshop (Los Angeles, CA, 4-10 February 1980) were included as controls throughout the study. Six patients were studied on two occasions and identical results for the HLA typing were obtained for each patient.

Streptococcal antibody tests. Antibody assays for the antistreptolysin 
Table I. Clinical Manifestations of Rheumatic Fever and their Frequency in 24 Caucasian and 48 Black Patients

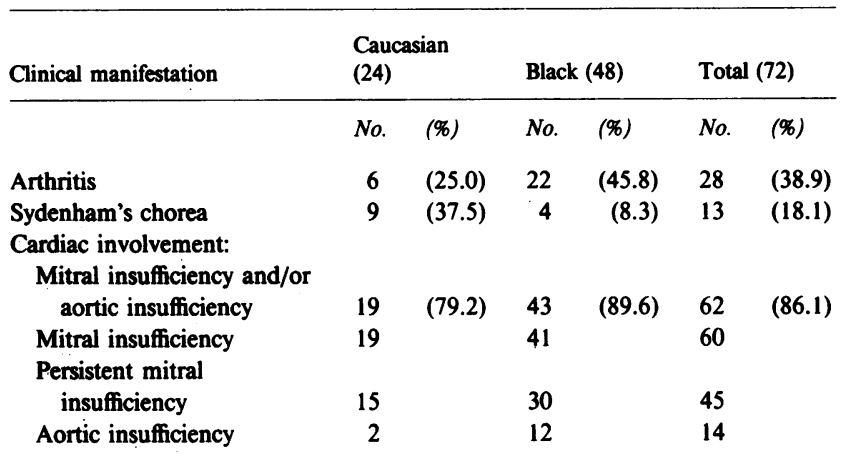

$\mathrm{O}$, anti-deoxyribonuclease $\mathrm{B}$, and the group A streptococcal carbohydrate (anti-ACHO) ${ }^{1}$ were performed as described previously (22). Persistence of the anti-ACHO was defined as presence of elevated levels of this antibody for $5 \mathrm{yr}$ or longer from the date of the acute rheumatic illness (38).

Statistical analysis. Relative risk (RR) or the number of times risk of disease is increased or decreased in individuals with a certain HLA marker in comparison to individuals without the marker, was calculated according to the method of Woolf as expanded by Svejgaard $(39,40)$. When the frequencies were sufficiently large $(>10)$, the classical chisquare statistic (41) was used to analyze contingency tables. Otherwise, an exact test based on the chi-square was used (42). In some instances, the strength of associations ( $P$ value) was tested by multiplying by the number of antigens at an HLA locus (e.g., DR) (43). The etiologic fraction (EF) or proportions of disease due to the HLA marker associated with the disease was calculated according to the method of Green (44).

\section{Results}

\section{Patients}

Rheumatic heart disease was the most common clinical manifestation in the patients studied, being present in $86 \%$ of the study patients. This high frequency of cardiac involvement reflects the predominant clinical feature of the patients that return for follow-up to the rheumatic fever clinics. All but two of the patients with cardiac involvement had mitral insufficiency. 12 patients had both mitral and aortic insufficiency, while two black patients had only aortic insufficiency. 45 of the $60(75 \%)$ patients with mitral valve disease had persistent mitral insufficiency, as defined by clinical evidence for the presence of that valvular lesion, both initially and throughout the course of their followup. Of these 45 patients, 40 had had persistent mitral insufficiency for at least $5 \mathrm{yr}$ before the time of the HLA study.

Of the 72 black or Caucasian patients studied, 50 had serial blood samplings during a follow-up period of at least $5 \mathrm{yr}$ beyond their initial episode. Of these 50 patients, 32 patients $(23$ black and 9 Caucasian) had persistence of the anti-ACHO.

Association of HLA phenotypes with susceptibility to rheumatic fever and its major clinical manifestations

Class I antigens. An initial survey of the frequency of the class I antigens previously reported to be positively associated with rheumatic fever (A3, A8, B5, BW15, BW17, and BW35), did

1. Abbreviations used in this paper: Anti-ACHO, antibody to group A streptoccal carbohydrate; EF, etiologic fraction; RR, relative risk. not reveal significantly increased frequencies of any of these antigens for our patients as a whole group, or when analyzed on the basis of race. Further analysis however, revealed that the class I antigen A23 was present at a significantly higher frequency and $\mathrm{A} 2$ at a significantly lower frequency in black patients than in controls (Table II). However, when the strengths of the associations were reduced by a factor dependent on the number of antigens at the two loci, as suggested by Grumet et al. (43), these findings became nonsignificant. HLA-B5 was more frequent in Caucasian patients than in controls, but not significantly so.

Class II antigens. A survey of the distribution of the class II (HLA-DR) antigen frequencies yielded an evident association between the DR2 and DR4 antigens and rheumatic fever in the black and Caucasian patients, respectively. The frequencies of the distribution of the class II antigens are shown in Tables III-VI.

In black patients with rheumatic fever the frequency of HLADR2 was significantly higher $(P<0.001)$ than its frequency in controls (Tables III and IV), even when the number of DR antigens tested (10) was considered (43). A highly significant positive association $(P<0.002)$ between DR2 was present for black patients with cardiac involvement and, in particular, those with persistent mitral insufficiency. An association of borderline significance was present between HLA-DR2 and arthritis $(P<0.05$, Fisher's Exact Test). Chorea showed a significant $(P<0.02)$ association with DR-1 antigen, and the presence of two major manifestations of rheumatic fever showed an association with DR-1 that is of borderline significance $(P=0.05)$, albeit the actual number of observations was small. A negative association $(P<0.05)$ with the DR5 or DR8 antigens was present in black patients with rheumatic fever and some of its major manifestations.

In Caucasian patients (Tables V and VI), the frequency of the association of HLA-DR4 with rheumatic fever was significant $(P<0.002)$. This association was also found for Caucasian patients with rheumatic carditis and persistent mitral insufficiency $(P<0.003)$, and for patients with two major manifestations of rheumatic fever. The presence of Sydenham's chorea showed a significant association $(P<0.04)$ with the same allele. A significant association $(P<0.001)$ was also found between rheumatic fever and HLA-DR9.

\section{Association of $H L A-D R$ antigens with persistence of the anti- $\mathrm{ACHO}$}

In the 32 patients who had persistence of the anti-ACHO for 5 yr or longer, there was a significant association with HLA-DR2

Table II. Class I HLA Phenotypes Showing Increased Frequency in Patients with Rheumatic Fever

\begin{tabular}{lllllllll}
\hline & & \multicolumn{3}{c}{$\begin{array}{l}\text { Frequency of } \\
\text { phenotype }\end{array}$} & & & & \\
\cline { 3 - 6 } HLA & Race & Patients & Controls & $x^{2}$ & P & RR & EF \\
\hline HLA-A2 & Black & $16 / 48$ & $38 / 68$ & 5.63 & $<0.02$ & 0.39 & $(-) 0.51$ \\
HLA-A23 & Black & $12 / 48$ & $6 / 68$ & 5.2 & $<0.02$ & 3.44 & $(+) 0.18$ \\
HLA-B5* & Caucasian & $3 / 24$ & $15 / 366$ & 3.23 & 0.09 & 3.34 & $(+) 0.09$
\end{tabular}

* HLA-B5 includes B51, B52, and B53. Data expressed in above fashion for comparison with previous studies in literature. 
Table III. Frequency of HLA-DR Alleles in 48 Black Patients with Rheumatic Fever and 64 Black Controls

\begin{tabular}{|c|c|c|c|c|c|c|c|c|c|c|c|c|c|c|c|c|}
\hline \multirow{3}{*}{$\begin{array}{l}\text { HLA } \\
\text { allele }\end{array}$} & \multirow{2}{*}{\multicolumn{2}{|c|}{$\begin{array}{l}\text { Controls } \\
\text { (64) }\end{array}$}} & \multirow{2}{*}{\multicolumn{2}{|c|}{$\begin{array}{l}\text { All rheumatics } \\
\text { (48) }\end{array}$}} & \multicolumn{6}{|c|}{ Major manifestation } & \multirow{2}{*}{\multicolumn{2}{|c|}{$\begin{array}{l}\text { Two major } \\
\text { manifestations } \\
\text { (19) }\end{array}$}} & \multirow{2}{*}{\multicolumn{2}{|c|}{$\begin{array}{l}\text { Persistent } \\
\text { mitral } \\
\text { insufficiency } \\
\text { (30) }\end{array}$}} & \multirow{2}{*}{\multicolumn{2}{|c|}{$\begin{array}{l}\text { Persistent anti- } \\
\text { ACHO (23) }\end{array}$}} \\
\hline & & & & & \multicolumn{2}{|c|}{ Arthritis (22) } & \multicolumn{2}{|c|}{ Chorea (4) } & \multicolumn{2}{|c|}{ Carditis (43) } & & & & & & \\
\hline & No. & $\%$ & No. & $\%$ & No. & $\%$ & No. & \% & No. & $\%$ & No. & $\%$ & No. & \% & No. & $\%$ \\
\hline DR1 & 10 & 15.6 & 11 & 22.9 & 6 & 27.3 & 3 & 75.0 & 10 & 23.3 & 7 & 36.8 & 6 & 20.0 & 6 & 26.1 \\
\hline DR2 & 15 & 23.4 & 26 & 54.2 & 10 & 45.5 & 2 & 50.0 & 23 & 53.5 & 8 & 42.1 & 17 & 56.7 & 16 & 69.6 \\
\hline DR3 & 19 & 29.7 & 12 & 25.0 & 6 & 27.3 & 2 & 50.0 & 10 & 23.3 & 5 & 26.3 & 5 & 16.7 & 8 & 34.8 \\
\hline DR4 & 5 & 7.8 & 7 & 14.6 & 4 & 18.2 & 0 & - & 6 & 14.0 & 3 & 15.8 & 4 & 13.3 & 2 & 8.7 \\
\hline DR5 & 26 & 40.6 & 10 & 20.8 & 3 & 13.6 & 0 & - & 10 & 23.3 & 3 & 15.8 & 8 & 26.7 & 2 & 8.7 \\
\hline DR6 & 14 & 21.9 & 12 & 25.0 & 5 & 22.7 & 0 & - & 12 & 27.9 & 5 & 26.3 & 8 & 26.7 & 4 & 17.4 \\
\hline DR7 & 13 & 20.3 & 5 & 10.4 & 2 & 9.1 & 0 & - & 5 & 11.6 & 2 & 10.5 & 4 & 13.3 & 4 & 17.4 \\
\hline DR8 & 11 & 17.2 & 3 & 6.3 & 2 & 9.1 & 0 & - & 2 & 4.7 & 1 & 5.3 & 2 & 6.7 & 1 & 4.3 \\
\hline DR9 & 4 & 6.3 & 1 & 2.1 & 1 & 4.5 & 0 & - & 0 & - & 0 & - & 0 & - & 0 & - \\
\hline
\end{tabular}

Frequencies are also shown for the various clinical manifestations of rheumatic fever (see text). Total number of patients in each category is shown in brackets under the respective heading.

Table IV. Significance of the Frequencies of DR Alleles in Black Patients

With Rheumatic Fever and Its Manifestations Compared with Controls Represented in Table III

\begin{tabular}{|c|c|c|c|c|c|c|c|c|c|c|}
\hline \multirow[b]{2}{*}{ Clinical manifestation } & & \multicolumn{9}{|l|}{ HLA-allele } \\
\hline & & DR1 & DR2 & DR3 & DR4 & DR5 & DR6 & DR7 & DR8 & DR9 \\
\hline \multirow[t]{4}{*}{ Rheumatic fever } & $x^{2}$ & 0.95 & 10.67 & 0.3 & 1.28 & 4.78 & 0.15 & 1.93 & 2.77 & 1.01 \\
\hline & $P$ & & $<0.001$ & & & $<0.03^{*}$ & & & & \\
\hline & $\mathbf{R R}$ & 1.61 & 3.86 & 0.79 & 2.02 & 0.39 & 1.19 & 0.46 & 0.32 & 0.32 \\
\hline & $\mathrm{EF}$ & 0.09 & $(+) 0.40$ & 0.07 & 0.07 & $(-) 0.33$ & 0.04 & 0.12 & 0.13 & 0.04 \\
\hline \multirow[t]{4}{*}{ Arthritis } & $\chi^{2}$ & 1.43 & 3.71 & 0.05 & 1.78 & 4.77 & 0.007 & 1.35 & 0.81 & 0.09 \\
\hline & $P$ & & $<0.05$ & & & $<0.02^{*}$ & & & & \\
\hline & $\mathbf{R R}$ & 2.03 & 2.72 & 0.89 & 2.62 & 0.23 & 1.05 & 0.39 & 0.48 & 0.71 \\
\hline & $\mathrm{EF}$ & 0.14 & $(+) 0.29$ & 0.03 & 0.11 & $(-) 0.45$ & 0.01 & 0.14 & 0.10 & 0.02 \\
\hline \multirow[t]{4}{*}{ Chorea } & $\chi^{2}$ & 5.34 & 1.29 & 0.69 & - & - & - & - & - & - \\
\hline & $P$ & 0.02 & & & & & & & & \\
\hline & $\mathbf{R R}$ & 16.2 & 3.27 & 2.37 & & & & & & \\
\hline & EF & $(+) 0.7$ & $(+) 0.35$ & 0.29 & & & & & & \\
\hline \multirow[t]{4}{*}{ Carditis } & $\chi^{2}$ & 0.97 & 9.7 & 0.54 & 1.03 & 3.4 & 0.51 & 1.35 & 3.3 & - \\
\hline & $P$ & & $<0.002$ & & & $<0.05^{*}$ & & & $<0.05^{*}$ & \\
\hline & $\mathbf{R R}$ & 1.64 & 3.76 & 0.72 & 1.91 & 0.44 & 1.38 & 0.52 & 0.24 & \\
\hline & EF & 0.09 & $(+) 0.39$ & 0.09 & 0.07 & $(-) 0.29$ & 0.08 & 0.11 & $(-) 0.15$ & \\
\hline \multicolumn{11}{|l|}{ Two major } \\
\hline \multirow[t]{4}{*}{ manifestations } & $\chi^{2}$ & 3.82 & 2.47 & 0.08 & 1.03 & 3.64 & 0.16 & 0.9 & 1.49 & - \\
\hline & $P$ & 0.05 & & & & $<0.04^{*}$ & & & & \\
\hline & $\mathbf{R} \mathbf{R}$ & 3.15 & 2.38 & 0.85 & 2.13 & 0.27 & 1.28 & 0.46 & 0.27 & \\
\hline & EF & $(+) 0.25$ & $(+) 0.24$ & 0.05 & 0.09 & $(-) 0.42$ & 0.06 & 0.12 & 0.14 & \\
\hline \multicolumn{11}{|l|}{ Persistent mitral } \\
\hline \multirow[t]{4}{*}{ insufficiency } & $x^{2}$ & 0.28 & 9.46 & 1.78 & 0.7 & 1.7 & 0.26 & 0.66 & 1.76 & - \\
\hline & $P$ & & $<0.002$ & & & & & & & \\
\hline & $\mathbf{R} \mathbf{R}$ & 1.35 & 4.27 & 0.47 & 1.82 & 0.53 & 1.30 & 0.60 & 0.34 & \\
\hline & EF & 0.05 & $(+) 0.43$ & 0.19 & 0.06 & $(-) 0.24$ & 0.06 & 0.09 & 0.13 & \\
\hline \multicolumn{11}{|l|}{ Persistent anti- } \\
\hline \multirow[t]{4}{*}{ ACHO } & $x^{2}$ & 1.21 & 13.82 & 0.20 & 0.02 & 6.35 & 0.21 & 0.09 & 2.00 & - \\
\hline & $P$ & & $<0.001$ & & & $<0.005^{*}$ & & & $<0.02^{*}$ & \\
\hline & $\mathbf{R R}$ & 1.91 & 7.47 & 1.26 & 1.12 & 0.14 & 0.75 & 0.83 & 0.22 & \\
\hline & $\mathrm{EF}$ & 0.12 & $(+) 0.60$ & 0.07 & 0.01 & $(-) 0.54$ & 0.06 & 0.04 & $(-) 0.16$ & \\
\hline
\end{tabular}

Statistical analysis calculated as described in Methods. $\chi^{2}$, Chi-square value. $P$, probability level. * Negative association. 
Table V. Frequency of HLA-DR Alleles in 24 Caucasian Patients with Rheumatic Fever and 285 Caucasian Controls

\begin{tabular}{|c|c|c|c|c|c|c|c|c|c|c|c|c|c|c|c|c|}
\hline \multirow{3}{*}{$\begin{array}{l}\text { HLA } \\
\text { allele }\end{array}$} & \multirow{2}{*}{\multicolumn{2}{|c|}{ Controls (285) }} & \multirow{2}{*}{\multicolumn{2}{|c|}{$\begin{array}{l}\text { All rheumatics } \\
\text { (24) }\end{array}$}} & \multicolumn{6}{|c|}{ Major manifestation } & \multirow{2}{*}{\multicolumn{2}{|c|}{$\begin{array}{l}\text { Two major } \\
\text { manifestations } \\
\text { (10) }\end{array}$}} & \multirow{2}{*}{\multicolumn{2}{|c|}{$\begin{array}{l}\text { Persistent } \\
\text { mitral } \\
\text { insufficiency } \\
\text { (15) }\end{array}$}} & \multirow{2}{*}{\multicolumn{2}{|c|}{$\begin{array}{l}\text { Persistent anti- } \\
\text { ACHO (9) }\end{array}$}} \\
\hline & & & & & \multicolumn{2}{|c|}{ Arthritis (6) } & \multicolumn{2}{|c|}{ Chorea (9) } & \multicolumn{2}{|c|}{ Carditis (19) } & & & & & & \\
\hline & No. & $\%$ & No. & $\%$ & No. & \% & No. & $\%$ & No. & $\%$ & No. & $\%$ & No. & \% & No. & $\%$ \\
\hline DR1 & 60 & 21.1 & 2 & 8.3 & 0 & - & 0 & - & 2 & 10.5 & 0 & - & 2 & 13.3 & 1 & 11.0 \\
\hline DR2 & 83 & 29.7 & 8 & 33.3 & 1 & 6.7 & 5 & 55.6 & 5 & 26.3 & 3 & 30.0 & 2 & 13.3 & 2 & 22.0 \\
\hline DR3 & 56 & 19.7 & 4 & 16.7 & 2 & 33.3 & 1 & 11.9 & 2 & 10.5 & 1 & 10.0 & 2 & 13.3 & 2 & 22.0 \\
\hline DR4 & 91 & 31.9 & 15 & 62.5 & 4 & 66.7 & 6 & 66.7 & 13 & 68.4 & 8 & 80.0 & 11 & 73.3 & 6 & 67.0 \\
\hline DR5 & 55 & 19.3 & 6 & 25.0 & 3 & 50.0 & 1 & 11.1 & 6 & 31.6 & 4 & 40.0 & 4 & 26.7 & 2 & 22.0 \\
\hline DR6 & 60 & 21.1 & 3 & 12.5 & 0 & - & 0 & - & 3 & 15.8 & 0 & - & 2 & 13.3 & 1 & 11.0 \\
\hline DR7 & 68 & 23.9 & 4 & 16.7 & 1 & 16.7 & 1 & 11.1 & 3 & 15.8 & 1 & 10.0 & 3 & 20.0 & 3 & 33.0 \\
\hline DR8 & 20 & 7.0 & 1 & 4.2 & 0 & - & 1 & 11.1 & 1 & 5.3 & 1 & 10.0 & 1 & 6.7 & 0 & - \\
\hline DR9 & 3 & 1.1 & 4 & 4.2 & 1 & 16.7 & 0 & - & 1 & 5.3 & 1 & 10.0 & 1 & 6.7 & 0 & - \\
\hline
\end{tabular}

Frequencies are also shown for the various clinical manifestations of rheumatic fever (see text). Total number of patients in each category is shown in brackets under the respective heading.

Table VI. Significance of Frequencies of DR Alleles in Caucasian Patients with Rheumatic Fever and Its Manifestations Represented in Table $V$

\begin{tabular}{|c|c|c|c|c|c|c|c|c|c|c|}
\hline \multirow[b]{2}{*}{ Clinical manifestations } & & \multicolumn{9}{|c|}{ HLA allele } \\
\hline & & DR1 & DR2 & DR3 & DR4 & DR5 & DR6 & DR7 & DR8 & DR9 \\
\hline \multirow[t]{4}{*}{ Rheumatic fever } & $x^{2}$ & 2.0 & 0.19 & 0.13 & 8.29 & 0.45 & 0.97 & 0.63 & 0.28 & 13.5 \\
\hline & $P$ & & & & 0.002 & & & & & $<0.001$ \\
\hline & $\mathbf{R R}$ & 0.34 & 1.22 & 0.82 & 3.55 & 1.39 & 0.54 & 0.64 & 0.58 & 18.8 \\
\hline & EF & 0.16 & 0.06 & 0.04 & $(+) 0.45$ & 0.07 & 0.11 & 0.09 & 0.03 & $(+) 0.16$ \\
\hline \multirow[t]{3}{*}{ Arthritis } & $\begin{array}{l}\chi^{2} \\
P\end{array}$ & - & 0.43 & 0.66 & 2.74 & 2.97 & - & 0.17 & - & 5.6 \\
\hline & $\mathbf{R} \mathbf{R}$ & - & 0.49 & 2.05 & 4.26 & 4.18 & & 0.64 & & 18.8 \\
\hline & EF & - & 0.18 & 0.17 & $(+) 0.51$ & 0.38 & & 0.09 & & 0.16 \\
\hline \multirow[t]{4}{*}{ Chorea } & $x^{2}$ & - & 2.65 & 0.39 & 4.07 & 0.37 & - & 0.74 & 0.22 & - \\
\hline & $P$ & & & & $<0.04$ & & & & & \\
\hline & $\mathbf{R R}$ & - & 3.04 & 0.51 & 4.26 & 0.52 & & 0.40 & 1.66 & \\
\hline & $\mathbf{E F}$ & - & 0.37 & 0.11 & $(+) 0.51$ & 0.10 & & 0.17 & 0.004 & \\
\hline \multirow[t]{4}{*}{ Carditis } & $x^{2}$ & 1.15 & 0.07 & 0.92 & 9.01 & 1.62 & 0.3 & 0.64 & 0.08 & 1.96 \\
\hline & $P$ & & & & $<0.002$ & & & & & \\
\hline & $\mathbf{R R}$ & 0.44 & 0.87 & 0.48 & 4.62 & 1.93 & 0.70 & 0.60 & 0.74 & 5.22 \\
\hline & $\mathbf{E F}$ & 0.13 & 0.40 & 0.11 & $(+) 0.54$ & 0.15 & 0.07 & 0.11 & 0.019 & 0.04 \\
\hline \multirow{5}{*}{$\begin{array}{l}\text { Two major } \\
\text { manifestations }\end{array}$} & & & & & & & & & & \\
\hline & $x^{2}$ & - & 0.004 & 0.55 & 7.16 & 2.39 & - & 0.95 & 0.13 & 3.8 \\
\hline & $P$ & & & & $<0.003$ & & & & & \\
\hline & $\mathbf{R R}$ & & 1.04 & 0.45 & 8.53 & 2.79 & & 0.36 & 1.47 & 10.44 \\
\hline & $\mathrm{EF}$ & & 0.01 & 0.12 & $(+) 0.71$ & 0.26 & & 0.18 & 0.03 & 0.09 \\
\hline \multirow{5}{*}{$\begin{array}{l}\text { Persistent mitral } \\
\text { insufficiency }\end{array}$} & & & & & & & & & & \\
\hline & $x^{2}$ & 0.5 & 1.62 & 0.36 & 8.76 & 0.48 & 0.51 & 0.11 & 0.003 & 2.57 \\
\hline & $P$ & & & & $<0.002$ & & & & & \\
\hline & $\mathbf{R} \mathbf{R}$ & 0.58 & 0.37 & 0.63 & 5.86 & 1.52 & 0.58 & 0.80 & 0.95 & 6.71 \\
\hline & $\mathbf{E F}$ & 0.10 & 0.22 & 0.08 & $(+) 0.61$ & 0.09 & 0.10 & 0.05 & 0.01 & 0.06 \\
\hline \multicolumn{11}{|l|}{ Persistent anti- } \\
\hline \multirow[t]{4}{*}{ ACHO } & $x^{2}$ & 0.5 & 0.2 & 0.04 & 4.07 & 0.047 & 0.50 & 0.42 & - & - \\
\hline & $P$ & & & & $<0.04$ & & & & & \\
\hline & $\mathbf{R R}$ & 0.46 & 0.70 & 1.17 & 4.26 & 1.19 & 0.47 & 1.60 & & \\
\hline & EF & 0.13 & 0.10 & 0.03 & $(+) 0.5$ & 0.04 & 0.13 & 0.12 & & \\
\hline
\end{tabular}

Statistical analysis calculated as described under Methods. $\chi^{2}$, Chi square value. $P$, probability level. 
in the black patients $(P<0.001)$ and with HLA-DR4 in the Caucasian patients $(P<0.04)$ (Tables III-VI).

An alternative analysis of the association of DR2 and DR4 with persistence of the anti-ACHO revealed that of the 21 black patients with the DR-2 phenotype, $16(76 \%)$ had persistence of the anti-ACHO, while only 7 of the 14 patients with other DR phenotypes had persistence of this antibody. Six of the nine (67\%) Caucasian patients with DR4 phenotype manifested persistence of the anti-ACHO compared with three of six Caucasian patients with other DR phenotypes. Neither of these differences, in this relatively small number of patients, were statistically significant. Similarly, the association of persistence of the antiACHO was examined in all 54 patients with either DR2 or DR4 and compared with the 21 patients negative for these phenotypes. Persistence of anti-ACHO was found in 28 of the 54 patients positive for DR2 or DR4, and in 7 of the 21 patients negative for DR2 or DR4. Analysis of these frequencies yielded a chisquare value of $2.04, \mathrm{RR}=2.15, \mathrm{EF}$ of 0.28 with a $P$ value of 0.15 .

Association of HLA-DR2 and DR4 phenotypes with persistence of the anti-ACHO in patients with or without persistent mitral insufficiency. The above findings raised the possibility that the observed association between the DR2 or DR4 antigens and persistence of the anti-ACHO may reflect the previously established association of persistence of this antibody with chronic mitral valve disease. To address this question, the frequencies of these alleles were determined separately on patients who had persistent anti-ACHO with or without mitral insufficiency. The results of this analysis (Table VII) revealed that, in black patients, the frequencies of DR2 in the two patient categories did not differ significantly, but that the frequency of this allele in either of the two patient categories was significantly higher $(P=0.0004-0.007)$ than its frequency in the normal control population. The availability of only two Caucasian patients with no mitral insufficiency precluded any conclusions regarding the significance of the frequency of DR4 in these patients.

\section{Discussion}

Previous studies by Falk and co-workers (26) on the association of class I HLA antigens with rheumatic fever, reported a decreased frequency of HLA-A3 in Caucasians with rheumatic

Table VII. Frequency of DR2 and DR4 Alleles in Patients With Persistent Anti-ACHO. With or Without Persistent Mitral Insufficiency

\begin{tabular}{|c|c|c|c|}
\hline Category & $\begin{array}{l}\text { Frequency } \\
\text { of allele }\end{array}$ & \multicolumn{2}{|l|}{$P$ value* } \\
\hline Black patients & DR2 & \multirow{4}{*}{$\begin{array}{l}\text { JNS } \\
]=0.0004\end{array}$} & \\
\hline With mitral insufficiency & $10 / 17$ & & \\
\hline No mitral insufficiency & $6 / 6$ & & $=0.007$ \\
\hline Controlsł & $15 / 64$ & & \\
\hline Caucasian patients & DR4 & & \\
\hline With mitral insufficiency & $5 / 7$ & NST- & \\
\hline No mitral insufficiency & $1 / 2$ & $\begin{array}{l}\mathrm{JNS} \\
\mathrm{J}\end{array}$ & \\
\hline Controlsł & $91 / 285$ & ]NS ] & \\
\hline
\end{tabular}

* Fisher's Exact Test. $P>0.05$.

¥ Refers to normal population in Tables III and V, for which frequency of the allele was determined in this study. fever. Caughey et al. (27) found increased frequencies of HLAA3 and HLA-B8 and decreased frequency of HLA-A 10 antigens in Maoris, as well as a decreased frequency of HLA-A28 with increased HLA-B17 antigens in Europeans with this disease. Leirisalo et al. (29) reported an increased frequency of HLAB35 in his initial study for Finnish patients with rheumatic fever, but could not confirm that finding in a subsequent study (45). Murray's study revealed an increase in HLA-B5 phenotype in his patients with rheumatic fever, but this finding proved to be not statistically significant (30). It is notable that Greenberg et al. (23) reported that HLA-B5 (currently designated B51, B52, B53) was associated with an increased response in vitro to streptococcal antigens, while Yoshinoya and Pope (33) found that patients with rheumatic fever who were positive for the HLAB5 antigen cluster demonstrated a significantly more pronounced immune response as measured by circulating immune complexes.

The results of our studies, however, did not reveal a significant association of the previously reported class I antigens with rheumatic fever in Caucasian or black patients. The frequency of HLA-23 was increased while that of HLA-A2 was decreased in the black patients. These associations become nonsignificant when reduced by the number of antigens tested for (43). Interestingly though, the association of the HLA-B5 cluster with rheumatic fever demonstrated the same trend observed in previous studies $(23,30,33)$. The frequency of this antigen group was also higher in our Caucasian patients than in their respective controls, but the differences, as in the preceding studies, did not reach statistical significance.

In contrast to the above, definite and highly significant associations were found between rheumatic fever and the class II HLA-DR antigens. As with previously described associations between HLA-DR antigens and a variety of human diseases, particularly collagen vascular diseases, the association appeared to be race-specific (46). HLA-DR2 and HLA-DR4 were present in a significantly higher frequency in black patients and in Caucasian patients with rheumatic fever, respectively, when compared with race-matched controls. The positive DR9 association with rheumatic fever in Caucasian patients may be more apparent than real, since the control frequencies listed give minimal estimates for this allele. Previously, some early results listed as DR4 may have been confirmed as DR9 on retesting. Nevertheless, the finding of 4 of 24 patients (17\%) positive for the DR9 allele is striking, albeit requiring confirmation in an expanded study.

Cardiac involvement, particularly mitral insufficiency, and Sydenham's chorea are considered the most specific of the clinical manifestations of rheumatic fever, while arthritis is the least specific (34). Therefore, it was not unexpected to find a highly significant association of mitral insufficiency with these two DR antigens in black and Caucasian patients, and of Sydenham's chorea in the Caucasian patients. The suggestion of a significant association between HLA-DR1, and the absence of an association with HLA-DR2, in the black patients with chorea should be interpreted with some reservation because of the small number of black patients (four) with this manifestation. The lack of a significant association between arthritis and the DR2 or DR4 alleles in both races reemphasizes the low specificity of this clinical manifestation for rheumatic fever. In addition, the number of Caucasian patients with arthritis was small.

The presence of two major clinical manifestations of rheumatic fever is a basis for the diagnosis of acute rheumatic fever 
according to the Jones criteria (34). While the presence of two major manifestations shows a highly significant association with DR4 in Caucasian patients $(P<0.008)$, this was not so for the DR2 antigen in black patients. Although the frequency of HLADR2 in these patients was relatively high (42\%) and approached that of the patients with carditis (53.5\%), the lack of a statistically significant association of the former again reflects the smaller number of patients involved.

Other investigators have examined the association of class II antigens with rheumatic fever. Patarroyo et al. (32) identified an alloantiserum (alloantiserum 883), derived from among 200 human sera surveyed, which reacted with B cells from 71-75\% of patients with rheumatic fever. In recent studies, Zabriskie et al. (47) confirmed the above findings using monoclonal antibodies with similar specificity as the 883 alloantiserum. Both the human alloantiserum and the monoclonal antibodies showed no reactivity with cell lines derived from individuals homozygous for the various MLC D-locus alleles (32), or with panels of cells with HLA-A, B, C and DR antigen specificity (47). The fact that the alloantiserum and the monoclonal antibodies did not react with known B cell antigens suggests that they possess specificity for an as yet undefined B cell antigen(s). The relationship of this $B$ cell antigen(s) to the DR alleles remains to be clarified.

Additionally, Patarroyo et al. (32) tested six antisera with known DR specificity (DR1, 2, 3, 5, 4/7, 4/7/10) for reactivity with leukocytes from normal controls, and patients with rheumatic fever from New York and Bogota, Colombia. The frequency of alloantigens detected by these six sera among the patients was not different from their controls. Our finding of the association of DR antigens with rheumatic fever appears to conflict with the results obtained by Patarroyo et al. (32). Possible reasons for the different results include both of the following. The first may relate to differences in the specificity of the DR antisera used. As listed above, only four of the sera used by Patarroyo (32) were monospecific, while the DR4 antisera appear to be heterospecific. The heterologous antigenic reactivity of the DR4 antiserum may have increased the frequency of reactivity with normal controls, thus reducing the significance of the differences between controls and patients. It is of note that in the data presented by Patarroyo et al. (32), the frequencies of DR reactivity in the patients, and the $R R$ values for associations are highest for DR2- and DR4-associated antisera, albeit the differences from controls are far lower than those obtained with the 883 alloantiserum and are not statistically significant. The second possible reason for the observed discrepancy may be related to geographical or racial differences in genetic background. Patarroyo et al. (32) do not present data related to the racial background of the subjects studied. It has been clearly established that DR antigen expression is disparate between races, both in frequencies as well as in patterns of reactivity to alloantisera (27, $30,46,48)$.

Despite the encountered differences, it is important to emphasize the similarity between our results and those reported by Patarroyo et al. (32). Both studies demonstrated a high incidence of expression of a B cell marker among patients with rheumatic fever. Our study extends this finding by demonstrating a racespecific association between certain major clinical manifestations of rheumatic fever and two of the conventional HLA-DR antigens. Furthermore, our study suggests an association between a DR antigen and the immune response of patients with rheumatic fever to a streptococcal antigen.

We have previously demonstrated a relationship between persistence of mitral insufficiency and persistence of the anti$\mathrm{ACHO}(22,38)$. This relationship was also evident in the present study. As shown in Tables IV and VI, there was a significant association between HLA-DR2 in black patients and HLA-DR4 in Caucasian patients with persistence of the anti-ACHO. In black patients, this association carried a higher chi-square value than all the major manifestations of rheumatic fever. Because of the inclusion of a high proportion of patients with mitral insufficiency, it was important to ascertain that the observed association between the DR2 and DR4 alleles and persistence of the anti-ACHO was not biased by patient selection. The results of the separate analysis of the data based on the presence or absence of mitral insufficiency, shown in Table VII, supports the association of persistence of the anti-ACHO with the HLADR2 genetic marker in the black patients. This observation is of particular importance because of previous studies showing that both the antibody response to the group A streptococcal carbohydrate in laboratory animals and in vitro human lymphocyte reactivity to streptococcal cell wall antigen(s) are under genetic control (49-51). The lack of a significant association when persistence of the antibody to the streptococcal carbohydrate is compared in individuals who are positive for HLA-DR2 or -DR4 with those who are negative for these phenotypes may be due to the small numbers of subjects or to the possibility that the gene controlling the antibody response to this streptococcal antigen is in linkage disequilibrium with the genes of the HLADR region.

Although the HLA-DR association with rheumatic fever was not universal for all patients, the finding of an association with HLA-DR2 in blacks or HLA-DR4 in Caucasians could be a useful marker for susceptibility to rheumatic fever and/or prediliction to rheumatic heart disease. The frequency of HLADR2/4 heterozygotes among patients with rheumatic fever was not different than in controls ( $7 \%$ vs. $5 \%$, respectively; chi-square value $=0.69$, R.R. $=1.55$ ). Thus the HLA-DR association we have demonstrated could be due to the presence of a diseaseassociated immune-response gene which is in linkage disequilibrium with the HLA-DR2 allele in blacks and with the HLADR4 allele in Caucasians. The primary susceptibility gene could reside at another D locus, at the complement or class III locus on chromosome six, or at another as yet undefined region. Further studies to examine frequencies of complement allotypes, or of subtypes or supra types of HLA class II alleles by restriction endonuclease fragment length polymorphisms using $\mathrm{DR} \alpha, \mathrm{DR} \beta$, DP $\alpha$, and DP $\beta$ complementary DNA probes could be most revealing in this regard.

Rheumatic fever is the only connective tissue disease in which the inciting factor is known. Preceding infection with the group A streptococcus is clearly required to trigger the acute rheumatic process. However, the precise immunopathogenic mechanisms leading to the clinical manifestations of rheumatic fever are not understood. The finding of a significant association between rheumatic fever and HLA-DR2 in blacks and HLA-DR4 in Caucasians, together with the finding of a high association of these HLA alleles with an immunological hyperresponsiveness to the streptococcal group-specific polysaccharide, are consistent with the hypothesis that rheumatic fever is the consequence of a genetically controlled immunological reaction to prior infection with group A streptococcus. However, it is necessary to emphasize again that our study was biased toward patients with rheumatic heart disease. Due to a decline in the incidence of new patients with acute rheumatic fever seen at our clinic, we were 
unable to accumulate an adequate number of patients fulfilling the criteria for acute rheumatic fever who did not have cardiac involvement. Additional studies will be needed to determine whether the strong DR association with rheumatic heart disease and persistance of antibody to the group A streptococcal carbohydrate can be confirmed for other major manifestations of this disease.

\section{Acknowledgments}

The authors wish to acknowledge the valuable assistance of Ervin Faulmann in the statistical analysis and the technical help provided by Rana Ayoub, Elaine Harden, and Edith Rosenbloom. We are also grateful to Drs. William Blanchard, Ira Gessner, Gerold L. Schiebler, Gladys Soler, Michael Steiner, Benjamin Victorica, and James G. White for making patients available for this study.

This work was supported by grant HL30059 from the National Institutes of Health.

\section{References}

1. Stollerman, G. 1975. Epidemiology of rheumatic fever. In Rheumatic Fever and Streptococcal Infections. Grune and Stratton, Inc., New York. 92.

2. Paul, J. R. 1957. The rheumatic family. In The Epidemiology of Rheumatic Fever. American Heart Association, New York. 125-130.

3. Ayoub, E. M. 1984. The search for host determinants of susceptibility to rheumatic fever: the missing link. Circulation. 69:197-201.

4. Read, F. E. M., A. Ciocco, and H. B. Taussig. 1938. Frequency of rheumatic manifestations among siblings, parents, uncles, aunts and grandparents of rheumatic and control patients. Am. J. Hyg. 27:719737.

5. Wilson, M. G., M. D. Schweitzer, and R. Lubschez. 1943. The familial epidemiology of rheumatic fever: genetic and epidemiologic studies. J. Pediatr. 22:468-492.

6. Wilson, M. G., and M. Schweitzer. 1954. Pattern of hereditary susceptibility in rheumatic fever. Circulation. 10:699-704.

7. Clarke, C. A., R. B. McConnell, and P. M. Sheppard. 1960. ABO blood groups and secretor character in rheumatic carditis. Br. Med. J. i:21-23.

8. Glynn, L. E., and E. J. Holborow. 1961. Relation between blood groups, secretor status and susceptibility to rheumatic fever. Arthritis Rheum. 4:203-207.

9. Buckwalter, J. A., G. S. Neifeh, and J. E. Auer. 1962. Rheumatic fever and the blood groups. Br. Med. J. ii:1023-1027.

10. Stevenson, A. C., and E. A. Cheeseman. 1953. Heredity and rheumatic fever: a study of 462 families ascertained by an affected child and 51 families ascertained by an affected mother. Ann. Eugen. (Lond.). 17:177-210.

11. Uchida, I. A. 1953. Possible genetic factors in the etiology of rheumatic fever. Am. J. Hum. Genet. 5:61-69.

12. Taranta, A., S. Torosdag, J. D. Metrakos, W. Jegier, and I. Uchida. 1961. Rheumatic fever in monozygotic and dizygotic twins. Proc. Int. Congr. Rheumatol., 10th, Minerva Medica, Torino. Turin, Italy. 96-98.

13. Spagnulo, M., and A. Taranto. 1968. Rheumatic fever in siblings. Similarity of its clinical manifestations. N. Engl. J. Med. 278:183-188.

14. DiSciascio, G., and A. Taranta. 1980. Rheumatic fever in children. Am. Heart J. 99:635-658.

15. Clark, C. A., R. B. McConnell, and P. M. Sheppard. 1960. ABO blood groups and secretor character in rheumatic carditis. Br. Med. J. i:21-23.

16. Rijsewijk, V., M. J. Haverkorn, and W. R. O. Goslings. 1963. Secretor status of streptococcus pyogenes Group A carriers and patients with rheumatic heart disease or acute glomerulonephritis. Br. Med. J. ii:542-543.

17. Dublin, T. D., A. D. Bernanke, E. L. Pitt, B. F. Massell, F. H.
Allen, and F. Amezcua. 1964. Red blood cell groups and ABH secretor system as genetic indicators of susceptibility to rheumatic fever and rheumatic heart disease. Br. Med. J. ii:775-779.

18. Swift, H. F. 1929. Rheumatic fever. J. Am. Med. Assoc. 92:20712083.

19. Rejholic, V. 1957. Incidence of rheumatic fever in relation to immunologic reactivity. Ann. Rheum. Dis. 16:23-30.

20. Zabriskie, J. B. 1974. Rheumatic fever: a streptococcal-induced autoimmune disease? In Infection and Immunology in the Rheumatic Disease. D. C. Dumonde, editor. Blackwell Scientific Publications, Oxford, England. 97-111.

21. Taranta, A. 1978. Post-streptococcal diseases: pathogenetic aspects of rheumatic fever and acute poststreptococcal glomerulonephritis. $\mathrm{Pa}$ thol. Annu. 8:333-357.

22. Dudding, B. A., and E. M. Ayoub. 1968. Persistence of streptococcal group A antibody in patients with rheumatic valvular disease. J. Exp. Med. 128:1081-1098.

23. Greenberg, L. J., E. D. Grey, and E. J. Yunis. 1975. Association of HLA-B5 and immune responsiveness in vitro to streptococcal antigens. J. Exp. Med. 141:935-943.

24. Read, S. E., V. A. Fischetti, V. Ultermohlen, R. F. Falk, and J. B. Zabriskie. 1974. Cellular reactivity studies to streptococcal antigens. Migration inhibition studies in patients with streptococcal infections and rheumatic fever. J. Clin. Invest. 54:439-450.

25. Gray, E. D., L. W. Wannamaker, E. M. Ayoub, A. E. Kholy, and Z. H. Abdin. 1981. Cellular immune responses to extracellular streptococcal products in rheumatic heart disease. J. Clin. Invest. 68: 665-671.

26. Falk, J. A., J. L. Fleischman, J. B. Zabriskie, and R. E. Falk. 1973. A study of HLA antigen phenotype in rheumatic fever and rheumatic heart disease patients. Tissue Antigens. 3:173-178.

27. Caughey, D. E., R. Douglas, W. Wilson, and I. B. Hassall. 1975. HLA antigens in Europeans and Maoris with rheumatic fever and rheumatic heart disease. J. Rheumatol. 2:319-322.

28. Joysey, V. C., J. H. Roger, F. Ashworth, W. Bullman, B. L. Hazleman, M. Lachmann, and P. G. Watson. 1977. Parallel studies of HLA antigens in patients with rheumatic heart disease and scleritis: comparisons with three control populations. J. Rheumatol. 4(Suppl. 3): 84-88.

29. Leirisalo, M., O. Lartinen, and A. Tiilikainen. 1977. HLA phenotypes in patients with rheumatic fever, rheumatic heart disease and Yersinia arthritis. J. Rheumatol. 4(Suppl. 3):78-83.

30. Murray, G. C., M. M. Montiel, and R. H. Persellin. 1978. A study of antigens in adults with acute rheumatic fever. Arthritis Rheum. 21:652-656.

31. Read, S. E., H. Reid, T. Poon-King, V. A. Fischetti, J. B. Zabriskie, F. T. Rapaport. 1977. HLA and predisposition to the nonsuppurative sequelae of group A streptococcal infections. Transplant. Proc. 9:543546.

32. Patarroyo, M. E., R. J. Winchester, A. Vejerano, A. Gibofsky, F. Chalem, J. B. Zabriskie, and H. G. Kunkel. 1979. Association of a B-cell alloantigen with susceptibility to rheumatic fever. Nature (Lond.). 278:173-174.

33. Yoshinoya, S., and R. M. Pope. 1980. Detection of immune complexes in acute rheumatic fever and their relationship to HLA-B5. J. Clin. Invest. 65:136-145.

34. Ad Hoc Committee to Revise the Jones criteria (modified) of the Council on Rheumatic Fever and Congenital Heart Disease of the American Heart Association. 1984. Jones criteria (revised) for guidance in the diagnosis of rheumatic fever. Circulation. 69:204A-208A.

35. Amos, B. 1979-1980. Cytotoxicity testing. In National Institute of Allergy and Infectious Diseases Manual of Tissue Typing Techniques. US Department of Health, Education and Welfare; Public Health Service, National Institutes of Health publication No. 80-545. 42-45.

36. Terasaki, P. I., D. Bernoco, M. S. Park, G. Ozturk, Y. Zuraki. 1978. Microdroplet testing for HLA-A, -B, -C, and -D antigens. Am. J. Clin. Pathol. 69:103-120.

37. Van Rood, J. A., and J. P. van Leeuwen. 1976. Simultaneous 
detection of two cell populations by two color fluorescence and application to the recognition of B-cell determinants. Nature (Lond.). 262:795-797.

38. Ayoub, E. M., and S. T. Shulman. 1980. Pattern of antibody response to the streptococcal $A$ carbohydrate in rheumatic patients with or without carditis. In Streptococcal Disease and the Immune Response. Academic Press, Inc., New York. 649-659.

39. Woolf, B. 1955. On estimating the relation between blood group and disease. Ann. Hum. Genet. 19:251-253.

40. Svejgaard, A., C. Jersild, L. Staub-Nielsen, and W. Bodmer. 1974. HLA antigens and disease: statistical and genetical considerations. Tissue Antigens. 4:95-99.

41. Snedecor, G. W., and W. G. Cochran. 1981. Statistical Methods. Iowa State University Press, Ames, Iowa. 228-253.

42. Agresti, A., D. Wackerly, and J. M. Boyett. 1979. Exact conditional test for cross classifications: approximation of attained significant levels. Psychometrica. 44:75-83.

43. Grumet, F. C., R. O. Payne, J. Conischi, and J. P. Krics. 1974. HLA antigens as markers for disease susceptibility and autoimmunity in Graves' disease. J. Clin. Endocrinol. Metab. 39:1115-1119.

44. Greene, A. 1982. The epidemiological approach to studies of association between HLA and disease. II. Estimation of absolute risks, etiological and preventive fraction. Tissue Antigens. 19:259-268.
45. Leirisalo, M., P. Koivuranta, and O. Laitinen. 1980. Rheumatic fever and its sequels in children: a follow-up study with HLA analysis. J. Rheumatol. 7:506-514.

46. Miller, M. L., and D. N. Glass. 1981. The major histocompatibility complex antigens in rheumatoid arthritis and juvenile arthritis. Bull. Rheum Dis. 31:21-25.

47. Zabriskie, J. B., D. Lavenchy, R. C. Williams, S. M. Fu, C. A. Yeadow, M. Fotino, and D. G. Braun. 1985. Rheumatic fever-associated B cell alloantigens as identified by monoclonal antibodies. Arthritis Rheum. 28:1047-1051.

48. Pollack, M. S., and R. Rich. 1985 . The HLA complex and the pathogenesis of infectious diseases. J. Infect. Dis. 151:1-8.

49. Eichman, K., and T. J. Kindt. 1971. The inheritance of individual antigenic specificities of rabbit antibodies to streptococcal carbohydrate. J. Exp. Med. 134:532-552.

50. Klapper, D. G., and T. J. Kindt. 1974. Idiotypic cross-reactions among anti-streptococcal antibodies in an inbred rabbit population. Scand. J. Immunol. 3:483-490.

51. Sasazuki, T., H. Kaneoka, Y. Nishimura, R. Kaneoka, M. Hayama, and H. Ohkuni. 1980. An HLA-linked immune suppression gene in man. J. Exp. Med. 152:297-313. 